\title{
The Use of Multiculturally-Competent Research Methods to Promote Social Justice in Counseling and Psychology
}

\section{Heather Z. Lyons and Denise H. Bike}

Loyola University Maryland

\begin{abstract}
Social justice enjoys a long history in the fields of counseling and psychology. Despite this, several authors have noted barriers to a more thorough integration of a social justice orientation into these fields. With this special issue we attempt to address some of these barriers by focusing on the ways that research may be used to promote social justice. Specifically, we aim to guide counselors and psychologists in the production and consumption of research that promotes social justice by modeling this research and providing recommendations for implementing it. With five interrelated papers, including this introduction paper and a conclusion paper, we hope to meet three major goals. First, we intend to extend the existing awareness and understanding of research that promotes social justice, especially where understudied populations (e.g., those experiencing material poverty, immigrants, people of color, LGBTQ individuals) are concerned. Second, we hope that by engaging in a discussion of socially just research we highlight one means of strengthening the relationship between research and practice. Third, we intend to offer "best practices" recommendations. In working toward these three goals, we hope to encourage rigor and a high standard for socially just research as well as an appreciation of diverse methodologies.
\end{abstract}

Keywords: Social justice, qualitative research, quantitative research, mixed methods research 


\section{Introduction}

Overlap exists in the aims of research that is deemed multiculturally competent and socially just. Indeed, both types of research strive to amplify the voices, strengths, and needs of those least heard, as well as to produce benefits for underserved populations. At the same time, when considering the nuances, differences may exist between multiculturally-competent and sociallyjust research. Among other differences are variations in focus and level of analysis. Specifically, multicultural competence may emphasize the well-defined and uniform competencies of counselors and psychologists versus the emphasis on subjectively-defined needs of marginalized populations from a social justice perspective. Furthermore, culture is a priority in the multicultural competence literature versus power and privilege in social justice literatures. In terms of level of analysis, multicultural competence tends to focus on microsystems such as the counseling relationship versus focus at the macro system or mesosystem-level in social justice. Furthermore, some debate exists about the extent to which existing articulations of multicultural competence truly reflect a social justice orientation (see Grayshield \& Mihecoby, 2010; Speight \& Vera, 2008; Vera \& Speight, 2003).

Multicultural competence has been defined as the knowledge, skills and awareness necessary for work (where "work" is primarily defined as counseling and psychotherapy) with multicultural populations (Singh et al., 2010; Vera \& Speight, 2003). However, with the recent revival of the social justice literature, a broader definition of multicultural competence has been encouraged to recognize the possibility for counselors and psychologists to "function as change agents at organizational, institutional, and societal levels" (Vera \& Speight, 2003, p. 255), a sentiment expressed throughout the counseling psychology literature (e.g., Toporek \& Reza, 2001).

Social justice is a term that can be difficult to define. Agreement on the common elements of existing definitions includes (a) the recognition of systematic differential access to power, information, or opportunity, and (b) attempts to remedy unequal access through redistribution of these resources (Crether, Rivera, \& Nash, 2008; Fouad, Gerstein, \& Toporek, 2006; Ratts, D'Andrea, \& Arredondo, 2004). These remedy efforts may take a variety of forms and can be initiated through the various roles that counselors and psychologists assume, including that of researcher (Fouad et al., 2006). However, there is generally an emphasis on the need to step out of traditionally-defined roles for counselors and psychologists (e.g., acting as an advocate).

Despite the fact that well articulated guidelines exist for those wishing to produce multiculturally competent research (e.g., American Psychological Association, 2002), additional direction may be useful for those endeavoring to conduct socially just research given the differences between the two concepts. We posit that the diversity of research methods available (broadly, identified here as qualitative, quantitative, and mixed methods) may be evaluated with regard to their relation to social justice. Specifically, after considering and addressing well-noted challenges to conducting research with multicultural populations (see Chang \& Sue, 2005), social justice research may be used to help address the mental health needs of under-researched populations, to characterize access barriers, and to identify health disparities.

The articles contained in this special issue focus on how research can provide a vehicle by which social justice practice can be enacted when researchers are conscious and deliberate about these intentions. Here, we will use Ponterotto, Mathew, and Raughley's (2013) adaption of Crethar et al.'s (2008, p. 270) definition of social justice counseling to define social justice research: 
Social justice research represents a multifaceted approach to research in which investigators strive to simultaneously promote human development and the common good through addressing challenges related to both individual and distributive justice. Social justice research includes empowerment of the individual as well as the active confrontation of injustice and inequality in society because they affect research participants as well as those in their systematic contexts.

As with other forms of research, social justice research may be classified by the philosophy of science positions informing it. Components of philosophical positions include ontology (i.e., the nature of being and reality), epistemology (i.e., ways of knowing), and axiology (i.e., value systems). Researchers making decisions about the ontological position informing their research endeavors would consider questions including whether reality is created or uncovered. Epistemology then describes researchers' decisions about the process of gathering or creating knowledge. Finally, axiology is the set of judgments and interpretations made about knowledge gathered or created (Crotty, 1998; Lyons, Bike, Johnson, \& Bethea, 2012; White \& Dotson, 2010). Naturally, these philosophical positions may be informed by a variety of factors including researchers' access to power and culture (Lyons et al., 2012). For example, the extent to which interpretations of data are valued over others may be a reflection of researchers' experiences (Chang \& Sue, 2005).

\section{Socially Just Research in Counseling and Psychology}

As has been indicated elsewhere, the emphasis on social justice is not new to the professions of counseling (Green, McCollum, \& Hays, 2008) or psychology (e.g., Fouad et al., 2006; Ivey \& Collins, 2003) but rather is at least a century old (Crethar et al., 2008; Hartung, \& Blustein, 2002). In recent times, instances of research that have been labeled as socially just appear in the counseling and psychology literatures and these fields may even be at the forefront of such research (Carter, 2003; Green et al., 2008). Furthermore, Singh et al. (2010) reported that consulting existing research stands as one of the most often used means of gaining training in social justice for students. Indeed, $73 \%$ of their sample spontaneously reported reliance on research as a means of gaining training in social justice. Similarly, when Caldwell and Vera (2010) interviewed those committed to social justice, these participants noted that education and training-which included "readings and scholarship" (p. 169)—contributed to their social justice orientation. Therefore, not only does social justice enjoy a long-standing history in the counseling and psychology literatures, but such research is a recognized means of helping to train future generations of counselors and psychologists.

At the same time that these gains have been evidenced and maintained, scholars have noted barriers to the full integration of a social justice orientation into counseling and psychology (Ivey \& Collins, 2003; Lewis, Ratts, Paladino, \& Toporek, 2011; Nilsson \& Schmidt, 2005; Singh et al., 2010) and frustration with the pace of this integration (Baluch, Pieterse, \& Bolden, 2004). Other researchers have noted the lack of social justice training at the graduate level (Goodman et al., 2004; Nilsson \& Schmidt, 2005; Singh et al., 2010). This noted lack of preparation likely includes research training, which may leave new professionals without the skills and knowledgebase needed to conduct socially-just research. Indeed, 97\% of Singh et al.'s (2010) participants, pre-doctoral psychology interns, noted barriers to social justice training, including 
lack of support from their home institutions. These barriers have been conceptualized as a rift between awareness and action (Nilsson \& Schmidt, 2005; Vera \& Speight, 2003). In other words, many of those who may identify with a social justice orientation may struggle with how to implement this orientation. Considering a developmental perspective, Buckley (1998) postulated that the final stage in developing one's social justice orientation is learning the tools to act on the will to engage in change efforts. In the present special issue we focus on this point of movement from awareness to action by providing support for counselors and psychologists who may lack the technical skills to integrate social justice practices into their research endeavors, while recognizing that other professional roles (e.g., counselor, advocate) may be more obvious points of entry.

\section{Social Justice and Multicultural Competence in Research}

The articles in this special issue focus on the practical ways research may be used to promote social justice (e.g., What does socially just research look like? What do socially just researchers do?) in an effort to assist this movement from awareness to action. These manuscripts are guided by principles identified by Crethar et al. (2008) as common to feminist, multicultural, and social justice counseling. These principles are equity, access, participation, and harmony. When equity (i.e., a subjectively defined sense of fairness) is applied to the research setting it may be applied to (a) the research process (e.g., ensuring that research team members are valued for their respective talents) as well as (b) the content and focus of research (e.g., choosing to study access to quality mental health care for those without health insurance) and (c) research outcomes (e.g., do findings fairly represent participants and communities?). Access can be defined as one's right to power, information, and opportunity. Research that is socially just is intended to diminish barriers to resources by asking relevant questions and distributing results in ways that are inviting to relevant communities and in a voice that is recognizable (Choudhuri, 2005; Morrow, Rakhsha, \& Castañeda, 2001). When socially just researchers thoroughly solicit participation from relevant community members, participants are provided the opportunity to help make decisions that may be of influence to them. Finally, when research is harmonious communities as a whole are benefitted above the needs of individuals.

\section{Purpose}

With five interrelated papers, including an introduction and a conclusion article, we hope to meet three major goals. First, we intend to extend the existing awareness and understanding of research that promotes social justice, especially where understudied populations (e.g., those experiencing material poverty, immigrants, people of color) are concerned. Second, we hope to illuminate the ways that research that is socially just may act to strengthen the relationship between research and practice. Third, we intend to offer "best practices" recommendations for those intending to utilize research in the promotion of social justice, despite criticisms of a social justice agenda in counseling and psychology (see Crethar et al., 2008). In working toward these three goals, we hope to encourage rigor and a high standard for socially just research as well as an appreciation of diverse methodologies. 


\section{About This Special Issue}

The authors of the first article following this introduction (Lyons, Bike, Ojeda, Rosales, Johnson, \& Flores, 2013) consider the need for qualitative researchers to address issues of power, selfdefinition, cultural values, and history in research involving participants from historically underserved populations. In the service of social justice, the authors of this manuscript contemplate the benefits of research that involves the community and provides researchers with holistic and healthy representations of underrepresented populations. Reflecting on the extant literature, they deliberate on those aspects of culture that may be particularly congruent with the qualitative research process. Furthermore, the authors make salient the ways that customs and values can be woven into the qualitative research process to facilitate greater cultural congruence and social justice. Given the potential social, economic and legal vulnerability of marginalized populations, the authors provide guidance for those aspects of the qualitative research process that might best ensure participant comfort and safety including making connections with the community, protocol translation, and recruiting culturally aware research teams.

In the second article, Cokley and Awad (2013) point out that despite the historical misuse of quantitative research with marginalized populations, an overwhelming majority of research published in counseling and psychology is quantitative. Therefore, counselors and psychologists should conduct their research in a socially just and multiculturally competent manner. The authors offer their definition of socially just quantitative research and provide suggestions for conducting it using examples from recent research. In quantitative research, the authors note that socially just and culturally competent planning and design may include using constructs rooted in the value systems of the populations being studied, choosing topics that expand our understanding of strengths of and solutions for historically marginalized populations, and incorporating awareness of the nuances of experiences within cultural identities. Socially just data collection considerations are similarly elucidated and include the benefits stemming from an investigator's insider status. Also discussed are considerations about balancing the quantitative researcher's imperative for random sampling with the social justice agenda of adequately sampling from underserved groups. The authors also acknowledge the importance of being inclusive of the variety of identities within a larger understudied population. Finally, the authors discuss a personal example of the difference between biased and perspectival interpretation of quantitative data and its implications for social justice. They conclude by sharing examples of potential downfalls of socially just research in terms of an authors' ultimate lack of control over how the results are used. As the authors note, "the problems lie not with the methods themselves, but with the users of the methods" (this issue, p. TBD). And thus, so do the solutions.

The third article (Ponterotto, Mathew, \& Raughley, 2013) assumes a somewhat different structure and approach from the articles on qualitative and quantitative research in this issue, both of which detail specific socially just and multiculturally competent practices across the phases of a research project. Mixed methods designs may incorporate the exemplar practices across the phases of a study as covered in the first and second articles. Therefore, these recommendations are relevant to mixed methods research and do not need repeating in a third article. Furthermore, counselors and psychologists may be less familiar with mixed methods research than qualitative or quantitative research (Ponterotto, Kuriakose, \& Granovskaya, 
2008), therefore an orientation to mixed methods philosophy, approaches, designs and challenges is warranted.

Given these factors, Ponterotto et al. (2013) begin with a description of the state of mixed methods research as well as the barriers to and benefits of culturally competent and socially just mixed methods research. The authors review exemplar mixed methods studies, with a focus on five studies particularly strong in their socially just mixed methods perspective. The authors conclude by providing a table demonstrating the breadth of design configurations available to mixed methods researchers and culturally varied topics covered. Finally, they present a decision tree designed to assist researchers pondering whether to conduct mixed methods research and which of the many approaches to mixed methods research to use.

Finally, in the concluding article, Fassinger and Morrow (2013) reflect on the preceding articles to develop a tentative set of best practices in multiculturally competent research with a specific focus on the role of social justice. These authors highlight the following aspects of research: (a) the role of researchers and the research team, (b) the focus of research, (c) selection of underlying paradigms and research method/designs, (d) power and relationships with research participants; and (f) data-gathering, analysis, and reporting.

\section{Conclusions}

In conclusion, the purpose of this special issue is to encourage counselors and psychologists to consider the ways that they may utilize the research process to enact social justice aims while maintaining the integrity of their method of choice. We hope to do this by providing recommendations for implementing this type of research and deliberating on best practices.

\section{Contact information}

Heather Z. Lyons, Ph.D., Associate Professor \& Director of Clinical Training, Department of Psychology, Loyola University Maryland

Email: HZLyons@loyola.edu

Denise H. Bike, Ph.D., Visiting Affiliate Assistant Professor, Department of Psychology, Loyola University Maryland 


\section{References}

American Psychological Association. (2002). Guidelines on multicultural education, training, research, practice, and organizational change for psychologists. Retrieved on December 13, 2010 from http://www.apa.org/pi/oema/resources/policy/multicultural-guideline.pdf.

Baluch, S. P., Pieterse, A. L., \& Bolden, M. A. (2004). Counseling psychology and social justice: Houston...we have a problem. The Counseling Psychologist, 32, 89-98.

Buckley, M. J. (1998). The catholic university as promise and project: Reflections in a Jesuit tradition. Washington, DC: Georgetown University.

Caldwell, J. C., \& Vera, E. M. (2010). Critical incidents in counseling psychology professionals' and trainees' social justice orientation development. Training and Education in Professional Psychology, 4, 163-176.

Carter, R. T. (2003). The counseling psychologist in the new millennium: Building a bridge from the past to the future. The Counseling Psychologist, 31, 5-15.

Chang, J., \& Sue, S. (2005). Cultural sensitive research: Where have we gone wrong and what do we need to do now? In M. G. Constantine \& D. W. Sue (Eds.). Strategies for Building Multicultural Competence in Mental Health and Educational Settings (pp. 229-246). Hoboken, NJ: John Wiley \& Sons, Inc.

Chouduri, D. D. (2005). Conducting culturally sensitive qualitative research. In M. G. Constantine \& D. W. Sue (Eds.). Strategies for Building Multicultural Competence in Mental Health and Educational Settings (pp. 269-282). Hoboken, NJ: John Wiley \& Sons, Inc.

Crethar, H. C., Rivera, E. T., \& Nash, S. (2008). In search of common threads: Linking multicultural, feminist, and social justice counseling paradigms. Journal of Counseling and Development, 86, 269-278.

Crotty, M. (1998). The foundations of social research: Meaning and perspective in the research process. London: Sage Publications.

Fassinger, R., \& Morrow, S. (2013). Toward best practices in quantitative, qualitative, and mixed-method research: A social justice perspective. Journal for Social Action in Counseling and Psychology, 5 (2), 69-83.

Fouad, N. A., Gerstein, L. H., \& Toporek, R. L. (2006). Social justice and counseling psychology in context. In R. L. Toporek, L. H. Gerstein, N. A. Fouad, G. Roysircar, \& T. Israel (Eds.). Handbook for social justice in counseling psychology (pp. 1-16). Thousand Oaks, CA: Sage Publications, Inc. 
Goodman, L. A., Liang, B., Helms, J. E., Latta, R.E., Sparks, E., \& Weintraub, S. R. (2004). Training counseling psychologists as social justice agents: Feminist and multicultural principles in action. The Counseling Psychologist, 32, 793-837.

Grayshield, L. \& Mihecoby, A. (2010). Indigenous ways of knowing as a philosophical base for the promotion of peace and justice in counseling education and psychology. Journal for Social Action in Counseling and Psychology, 2, 1-16.

Green, E. J., McCollum, V. C., \& Hays, D. G. (2008). Teaching advocacy counseling within a social justice framework: Implications for school counselors and educators. Journal for Social Action in Counseling and Psychology, 1, 14-30.

Hartung, P. J., \& Blustein, D. L. (2002). Reason, intuition, and social justice: Elaborating on Parson's Career Decision-Making Model. Journal of Counseling \& Development, 80, 4147.

Ivey, A. E., \& Collins, N. M. (2003). Social justice: A long-term challenge for counseling psychology. The Counseling Psychologist, 31, 290-298

Lewis, J. A., Ratts, M. J., Paladino, D. A., \& Toporek, R. L. (2011). Social justice counseling and advocacy: Developing new leadership roles and competencies. Journal for Social Action in Counseling and Psychology, 3, 5-16.

Lyons, H. Z., Bike, D. H., Johnson, A., \& Bethea, A. (2012). Culturally competent research with people of African descent. Journal of Black Psychology, 38, 153-171.

Morrow, S. L., Rakhsha, G., \& Castañeda, C. L. (2001). Qualitative research methods for multicultural counseling. In J. G. Ponterotto, J. M. Casas, L. A. Suzuki, \& C. M. Alexander (Eds.), Handbook of multicultural counseling (2nd ed., pp. 575-603). Thousand Oaks, CA: Sage Publications.

Nilsson, J. E., \& Schmidt, C. K. (2005). Social justice advocacy among graduate students in counseling: An initial exploration. Journal of College Student Development, 46, 267-279.

Ponterotto, J. G., Kuriakose, G., \& Granovskaya, Y. (2008). Counseling and psychotherapy. In C. Willig \& W. Stainton-Rogers (Eds.), The Sage handbook of qualitative research in psychology (pp. 455-471). London: Sage.

Ponterotto, J. G., Mathew, J., \& Raughley, B. (2013). The value of mixed methods designs to social justice research in counseling and psychology. Journal for Social Action in Counseling and Psychology, 5(2), 42-68.

Ratts, M., D'Andrea, M., \& Arredondo, P. (2004). Social justice counseling: 'Fifth force' in field. Alexandria, VA: American Counseling Association.

Singh, A. A., Hofsess, C. D., Boyer, E. M., Kwong, A., Lau, A. S. M., McLain, M. \& Haggins, K. L. (2010). Social justice and counseling psychology: Listening to the voices of doctoral trainees. The Counseling Psychologist, 38, 766-795. 
Speight, S. L., \& Vera, E. M. (2008). Social justice and counseling psychology: A challenge to the profession. In S. D. Brown \& R. Lent (Eds.), Handbook of counseling psychology (pp. 54-67). Hoboken, NJ: Wiley \& Sons.

Toporek, R. L., \& Reza, J. V. (2001). Context as a critical dimension of multicultural counseling: Articulating personal, professional, and institutional competence. Journal of Multicultural Counseling and Development, 29, 13-30.

Vera, E. M., \& Speight, S. L. (2003). Multicultural competence, social justice, and counseling psychology: Expanding our roles. The Counseling Psychologist, 31, 253-272.

White, A. M., \& Dotson, W. (2010). It takes a village to raise a researcher: Narrative interviewing as intervention, reconciliation, and growth. Journal of Black Psychology, 36, 75-97. 